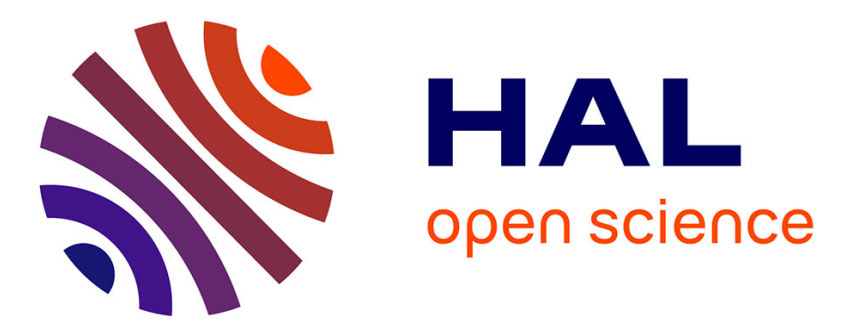

\title{
Human hydroxytyrosol's absorption and excretion from a nutraceutical
}

\author{
Olha Khymenets, M. Carmen Crespo, Olivier O. Dangles, Njara \\ Rakotomanomana, Cristina Andres-Lacueva, Francesco Visioli
}

\section{- To cite this version:}

Olha Khymenets, M. Carmen Crespo, Olivier O. Dangles, Njara Rakotomanomana, Cristina AndresLacueva, et al.. Human hydroxytyrosol's absorption and excretion from a nutraceutical. Journal of Functional Foods, 2016, 23, pp.278-282. 10.1016/j.jff.2016.02.046 hal-02639403

\section{HAL Id: hal-02639403 \\ https://hal.inrae.fr/hal-02639403}

Submitted on 28 May 2020

HAL is a multi-disciplinary open access archive for the deposit and dissemination of scientific research documents, whether they are published or not. The documents may come from teaching and research institutions in France or abroad, or from public or private research centers.
L'archive ouverte pluridisciplinaire HAL, est destinée au dépôt et à la diffusion de documents scientifiques de niveau recherche, publiés ou non, émanant des établissements d'enseignement et de recherche français ou étrangers, des laboratoires publics ou privés. 


\title{
Human hydroxytyrosol's absorption and excretion from a nutraceutical
}

\author{
Olha Khymenets ${ }^{a, 1}$, M. Carmen Crespo ${ }^{b, 1}$, Olivier Dangles ${ }^{c}$, \\ Njara Rakotomanomana ', Cristina Andres-Lacueva a, \\ Francesco Visioli ${ }^{b, d, *}$ \\ ${ }^{a}$ Biomarkers and Nutritional \& Food Metabolomics Research Group, Nutrition and Food Science Department, XaRTA, INSA, Pharmacy \\ Faculty, University of Barcelona, Barcelona, Spain \\ ${ }^{\mathrm{b}}$ Laboratory of Functional Foods, Madrid Institute for Advanced Studies (IMDEA) - Food, UAM + CSIC, Madrid, Spain \\ c University of Avignon, INRA, UMR 408, Avignon, France \\ d Department of Molecular Medicine, University of Padova, Italy
}

Keywords:

Hydroxytyrosol

Supplements

Bioavailability

Mass spectrometry

Metabolites

Polyphenols
Among the various (poly)phenols that are being sold as such or as part of a more complex mixture, hydroxytyrosol (HT) is the only one that bears a European Food Safety Authority health claim. Therefore, several HT-based products are being developed and sold and it becomes necessary to evaluate its accessibility following ingestion. Twenty-one volunteers were recruited for a randomized, crossover, placebo-controlled, and double-blind intervention study. We performed a Latin square design: after one-week washout, i.e. olive-free diet, subjects were randomly assigned to the placebo (maltodextrin), 5, or $25 \mathrm{mg} /$ day HT group. Twenty-four hour urine samples were collected after the intervention week, and baseline urines were collected the week before the study and during periods of washout. The results show that HT given as the foremost component of a nutraceutical preparation is bioavailable and is recovered in the urine chiefly as sulphate- $3^{\prime}$.

\section{1.}

Introduction

The nutraceutical and functional food market is rapidly expanding and several new products enter the market on a daily basis (Mahabir, 2014; Tome-Carneiro \& Visioli, 2015). Of note, such products are rarely tested in controlled human trial settings and the efficacy of individual molecules or raw extracts is often questionable. In addition, the bioavailability of individual molecules or active principle(s) is seldom assessed, in part because of technical limitations and lack of proper equipment.

Among the various (poly)phenols that are being sold as such or as part of a more complex mixture, hydroxytyrosol (HT) is the only one that bears a European Food Safety Authority health claim (EFSA Panel on Dietetic Products, 2011). Therefore, several HT-based products are being developed and sold (Visioli \& Bernardini, 2011) and it becomes necessary to evaluate accessibility of HT following ingestion. It is noteworthy that HT bioavailability has been reported after extra virgin olive oil

\footnotetext{
* Corresponding author. Department of Molecular Medicine, University of Padova, Viale G. Colombo 3, 35121 Padova, Italy. Tel.: +390498276107; fax: +3902700426106 .

E-mail address: francesco.visioli@unipd.it (F. Visioli).

1 These authors contributed equally to this work.
} 
administration (Caruso, Visioli, Patelli, Galli, \& Galli, 2001; Miro-Casas et al., 2003), yet never after the intake of HTcontaining supplements, with the exception of one study with pure HT (Gonzalez-Santiago, Fonolla, \& Lopez-Huertas, 2010).

In this study, we report the urinary excretion of HT (as such and as its metabolites) after its administration to healthy volunteers.

\section{Materials and methods}

\subsection{Standards and chemicals}

Hydroxytyrosol (HT, 98\% purity) standard was purchased from Extrasynthese (France). HT 3'-O- and 4'-O-glucuronides (HTG-3' and HT-G-4', 86\% and 97\% purity, respectively) were synthesized as previously described (Giordano, Dangles, Rakotomanomana, Baracchini, \& Visioli, 2015). HT 3'-Osulphate (HT-S-3', 98\% purity) standard was bought from Toronto Research Chemicals Inc. (Toronto, ON, Canada). Hydroxyphenylpropanol (HOPhPr, 99\% purity), used as the internal standard (ISTD), was purchased from Sigma-Aldrich (St. Louis, MO, USA).

LC-grade solvents methanol and ACN were purchased from Scharlau Chemie, S.A. (Sentmenat, Spain). Ammonium acetate and glacial acetic acid were purchased from Panreac Química, S.A.U. (Castellar del Vallés, Spain). Ultrapure water (Milli-Q) was obtained from Millipore (Bedford, MA, USA).

The capsules that we administered were elaborated from an olive mill waste water extract preparation called Hytolive ${ }^{\circledR}$, supplied by the company Genosa ID, S.L. (Madrid, Spain).

\subsection{Subjects and study design}

The study protocol was approved by the local ethics committee and written informed consent was obtained from all subjects prior to starting the trial. This work was carried out in accordance with The Code of Ethics of the World Medical Association (Declaration of Helsinki) and is registered at ClinicalTrials.gov (identifier: NCT02273622).

Samples of this research were obtained from a previous intervention study, whose objective was to evaluate the effect of HT on the gene expression of Phase II enzymes (Crespo et al., 2015). Briefly, twenty-one volunteers were recruited for a randomized, crossover, placebo-controlled, and double-blind intervention study. The design of this study is shown in Fig. 1. We performed a Latin square design: after one-week washout, i.e. olive-free diet, subjects were randomly assigned to the placebo (maltodextrin) group, $5 \mathrm{mg}$ /day HT group, or $25 \mathrm{mg} /$ day HT (Hytolive ${ }^{\circledR}$ ) group. Baseline characteristics of participants and inclusion and exclusion criteria are given in detail in Supplementary Information 1 (S.I.1 in Appendix S1). Volunteers were given dietary guidelines (Supplementary Information 2, S.I.2 in Appendix S1) that included abstention from olive products and limitation of high-polyphenol foods and alcohol (Crespo et al., 2015). Twenty-four hour urine samples were collected after the intervention week, and baseline urines were collected the week before the study and during periods of washout, and immediately stored at $-80^{\circ} \mathrm{C}$.

\subsection{Pretreatment and processing of the urine samples}

A total of 63 24-hour (from 21 volunteers, collected in the three experimental phases, after administration of the supplement) and 42 basal urine samples (collected during the final days of the second and third washout periods) were analysed.

All urine samples were thawed, vortexed, and centrifuged at $9000 \times g$ for $5 \mathrm{~min}$ at $4{ }^{\circ} \mathrm{C}$. The supernatant $(20 \mu \mathrm{L})$ from each urine sample was diluted with $0.1 \%$ acetic acid by a factor of 10 (1:10 vol:vol) for detection of HT and its glucuronidate metabolites and by a factor of 50 (1:50 vol:vol) for its sulphates (HT-S-3'and HT-S-4'). Calibration standards of 5-10-25-50-100250-500-1000 ng/mL for HT and 20-40-100-200-400-1000-2000$4000 \mathrm{ng} / \mathrm{mL}$ for HT-G-3', HT-G-4' and HT-S-3' in blank human urine were processed like the 10 -fold diluted samples. An internal standard (HOPhPr) was used at the final concentration of $500 \mathrm{ng} / \mathrm{mL}$ in all cases. Samples and calibration curves were distributed in 96-well plates and $2 \mu \mathrm{L}$ of each were injected in randomized order.

\subsection{Sample analysis}

LC-MS/MS analysis of diluted samples was performed on the Agilent (Santa Clara, CA, USA) 1290 Infinity Binary LC system coupled to an AB SCIEX QTRAP $® 6500$ spectrophotometer. Acquity UPLC BEH C18 $1.7 \mu \mathrm{m}, 2.1 \times 5 \mathrm{~mm}$ analytical column (Waters) at $40^{\circ} \mathrm{C}$ and $1 \mathrm{mM}$ ammonium acetate at pH 5.0 and $100 \%$ ACN as aqueous (A) and organic (B) mobile phases, respectively, were used for separation (Khymenets et al., 2011; Kotronoulas et al., 2013). Next, gradient elution (B\% (v/v), t (min)) at flow of $0.4 \mathrm{~mL} / \mathrm{min}$ was applied: (1\%, 0-3); (1-20\%, 3-3.2); (20\%, 3.2-4.5); (20-95\%, 4.5-4.8); (95\%, 4.8-5.3); (95-1\%, 5.3-5.5); (1\%, 5.5-6.5). Common MS parameters were as follows: ion spray voltage (IS) -4500.00 , source temperature (TEM) $600{ }^{\circ} \mathrm{C}$, curtain

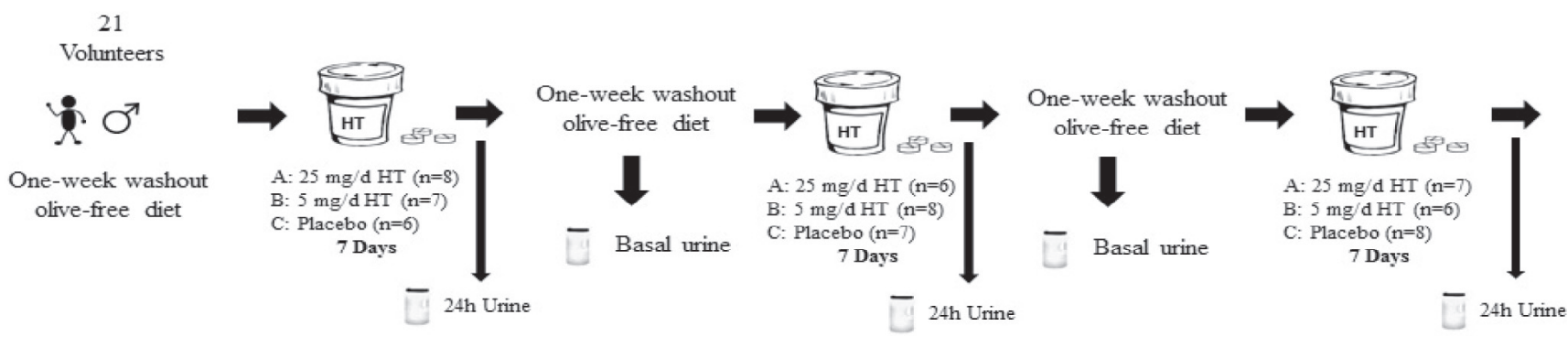

Fig. 1 - Study design. 
gas (CUR) 20.00 psi, ion source gas 1 (GS1) and gas 2 (GS2) 50.00 psi each, collision-activated dissociation (CAD) 3.00 psi, entrance potential (EP) -10.00 and cell exit potential (CXP) 13.00. The data were collected under negative ionization in multiple reaction monitoring mode (MRM) with following settings for compound fragmentations (declustering potential, DP: V; collision energy, CE: eV): HT 153- $\rightarrow 123^{-}$(DP: -55 ; CE: -20$)$; HTG-3' and HT-G-4' 329- $\rightarrow$ 153- (DP: -60 ; CE: -30 ); HT-S-3' and HTS-4' $233^{-} \rightarrow 153^{-}$(DP: -60 ; CE: -25 ) and HOPhPr 151- $\rightarrow 121^{-}$(DP: -65; CE: -22). HT, HT-G-3', HT-G-4' and HT-S-3' were quantified using calibration curves constructed with corresponding standards. HT-S-4' has been identified only in samples with high concentration of HT-S-3'; its concentration was estimated using slope of HT-S-3' calibration curve. The method based on LCMS/MS analysis for HT and its glucuronidated and sulphated metabolites in diluted urine samples was successfully validated, showing good linearity $\left(r^{2} \geq 0.99\right.$ in all cases) and following sensitivity (LOQs): 5 and $20 \mathrm{ng} / \mathrm{mL}$ urine for HT and its metabolites (glucuronides and sulphate), respectively. Intra- and inter-day precision and accuracy results were according to the standard requirements (U.S. Department of Health and Human Services, 2001) for method validation criteria: RSD\% and ERR\% were $<20 \%$ (except HT-S-3', where they were $\leq 28 \%$, due to the impact of ever existing endogenous metabolite) for low and $<15 \%$ (all compounds) for medium and high concentrations of tested standards.

The results were processed using Analyst 1.6.2 Software (AB SCIEX) and then statistically analysed. The final results, expressed as concentrations (ng/mL urine) of HT, HT-G-3', HTG-4', HT-S-3' and HT-S-4', are shown in Supplementary Table 1 (S.T.1 in Appendix S1).

\subsection{Statistical analysis}

Data were analysed with $\mathrm{R}$ Statistical Software version 3.1.1. Continuous descriptive variables were expressed as means \pm SEM. Two-way repeated measures ANOVA was used to evaluate the effects of time (basal and 24-hour urine), treatment $(\mathrm{A}, \mathrm{B}, \mathrm{C})$ and the time $\times$ treatment interaction. A Bonferroni correction for multiple analyses was applied and models were adjusted for age and sequence ( $\mathrm{ABC} / \mathrm{CAB} / \mathrm{BCA})$ as covariates. All statistical analyses were considered as bilateral and significance was set at $p<0.05$.

\section{Results}

The administration of a standardized, 10\%-HT nutraceutical resulted in a dose-dependent urinary excretion of HT and its metabolites (Table 1). These changes were statistically significant and were more pronounced for HT-S-3'. Of note, this molecule was also detected in urines from placebo-treated subjects, possibly as a consequence of endogenous HT production and excretion (Perez-Mana et al., 2015a,b). Inter-individual variability varied, but was - on average - 10\%.

Quantitatively, the total amount of HT and its metabolites recovered in the urine accounted for $21 \%$ (for the $25 \mathrm{mg}$ dose) to $28 \%$ (for the $5 \mathrm{mg}$ dose) of the administered dose (Table 2).

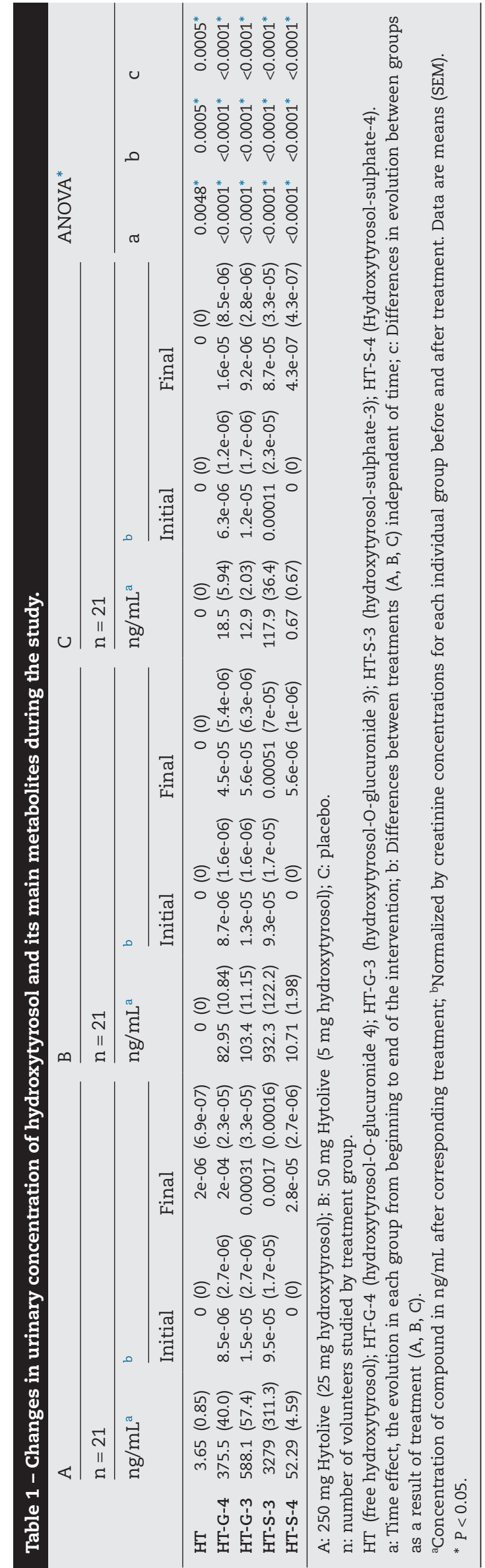




\begin{tabular}{rllllllllll}
\multicolumn{7}{c}{ Table 2 } & Twenty-four hour urine excretion of hydroxytyrosol and its main metabolites (as milligrams). \\
$\begin{aligned} \text { Dose } \\
(\mathrm{mg})\end{aligned}$ & $\begin{array}{l}\text { HT } \\
(\mathrm{mg})\end{array}$ & $\begin{array}{l}\text { HT } \\
(\%)\end{array}$ & $\begin{array}{l}\text { HT-G-4 } \\
(\mathrm{mg})\end{array}$ & $\begin{array}{l}\text { HT-G-4 } \\
(\%)\end{array}$ & $\begin{array}{l}\text { HT-G-3- } \\
(\mathrm{mg})\end{array}$ & $\begin{array}{l}\text { HT-G-3 } \\
(\%)\end{array}$ & $\begin{array}{l}\text { HT-S-3 } \\
(\mathrm{mg})\end{array}$ & $\begin{array}{l}\text { HT-S-3 } \\
(\%)\end{array}$ & $\begin{array}{l}\text { HT-S-4 } \\
(\mathrm{mg})\end{array}$ & $\begin{array}{l}\text { HT-S-4 } \\
(\%)\end{array}$ \\
\hline 0 & 0.00 & 0.00 & 0.03 & 0.00 & 0.02 & 0.00 & 0.14 & 0.00 & 0.00 & 0.00 \\
5 & 0.00 & 0.00 & 0.11 & 2.23 & 0.14 & 2.78 & 1.18 & 23.1 & 0.01 & 0.26 \\
25 & 0.00 & 0.02 & 0.46 & 1.83 & 0.72 & 2.87 & 4.15 & 16.6 & 0.07 & 0.28 \\
\hline
\end{tabular}

0: Placebo; 5: $5 \mathrm{mg}$ hydroxytyrosol; 25: $25 \mathrm{mg}$ hydroxytyrosol.

HT: free hydroxytyrosol; HT-G-4: hydroxytyrosol-O-glucuronide 4; HT-G-3: hydroxytyrosol-O-glucuronide 3; HT-S-3: hydroxytyrosol-sulphate3; HT-S-4: hydroxytyrosol-sulphate-4.

\section{Table 3 - Twenty-four hour urine excretion of hydroxytyrosol and its main metabolites (as micromoles).}

\begin{tabular}{|c|c|c|c|c|c|c|c|c|c|c|c|c|}
\hline $\begin{array}{l}\text { Dose } \\
(\mu \mathrm{M})\end{array}$ & $\begin{array}{l}\mathrm{HT} \\
(\mu \mathrm{M})\end{array}$ & $\begin{array}{l}\text { HT } \\
(\%)\end{array}$ & $\begin{array}{l}\text { HT-G-4 } \\
(\mu \mathrm{M})\end{array}$ & $\begin{array}{l}\text { HT-G-4 } \\
(\%)\end{array}$ & $\begin{array}{l}\text { HT-G-3- } \\
(\mu \mathrm{M})\end{array}$ & $\begin{array}{l}\text { HT-G-3 } \\
(\%)\end{array}$ & $\begin{array}{l}\text { HT-S-3 } \\
(\mu \mathrm{M})\end{array}$ & $\begin{array}{l}\text { HT-S-3 } \\
(\%)\end{array}$ & $\begin{array}{l}\text { HT-S-4 } \\
(\mu \mathrm{M})\end{array}$ & $\begin{array}{l}\text { HT-S-4 } \\
(\%)\end{array}$ & $\begin{array}{l}\text { Total } \\
(\mu \mathrm{M})\end{array}$ & Total excreted\% \\
\hline 0 & 0.00 & 0.00 & 0.02 & 0.00 & -0.01 & 0.00 & -0.26 & 0.00 & 0.00 & 0.00 & -0.05 & 0.00 \\
\hline 32.4 & 0.00 & 0.00 & 0.22 & 0.67 & 0.27 & 0.84 & 3.47 & 10.7 & 0.04 & 0.14 & 0.80 & 12.4 \\
\hline 162 & 0.02 & 0.01 & 1.10 & 0.68 & 1.72 & 1.06 & 13.5 & 8.33 & 0.22 & 0.13 & 3.32 & 10.2 \\
\hline
\end{tabular}

0: Placebo; $3.2 \mathrm{E}-5 \mu \mathrm{M}$ : $5 \mathrm{mg}$ hydroxytyrosol; $16 \mathrm{E}-5 \mu \mathrm{M}$ : $25 \mathrm{mg}$ hydroxytyrosol.

HT: free hydroxytyrosol; HT-G-4: hydroxytyrosol-O-glucuronide 4; HT-G-3: hydroxytyrosol-O-glucuronide 3; HT-S-3: Hydroxytyrosol-sulphate3; HT-S-4: Hydroxytyrosol-sulphate-4.

$\mu \mathrm{M}$ : micromole; Total

$(\mu \mathrm{M})$ : Total micromole as the sum of compounds found in urine samples; Total excreted

$(\mu \mathrm{M})$ : Total percentage as the sum of compounds recovered in urine.

Again, the major metabolite we detected was HT-S-3', which accounted for $23.6 \%$ (for the $5 \mathrm{mg}$ dose) to $16.6 \%$ (for the $25 \mathrm{mg}$ dose) of the administered HT.

Quantitatively, as we represent in Table 2, the total amount of $\mathrm{HT}$ recovered in the urine was minimal and accounted for $0.02 \%$ (only for the $25 \mathrm{mg}$ dose). For others metabolites, we observed a dose-dependent increase in their excretion. Again, the major metabolite we detected was HT-S-3', which accounted for $23.1 \%$ (for the $5 \mathrm{mg}$ dose) and $16.6 \%$ (for the $25 \mathrm{mg}$ dose) of the administered HT, followed by HT-G-3' with $2.78 \%$ (for the $5 \mathrm{mg}$ dose) and $2.87 \%$ (for the $25 \mathrm{mg}$ dose).

When results were expressed as micromole\% (in order to compare the different excreted compounds; Table 3), the total per cent excretion of all components dropped to $12.4 \%$ (for the $5 \mathrm{mg}$ dose) and $10.2 \%$ (for the $25 \mathrm{mg}$ dose). The per cent excretion of HT-S-3' dropped to $10.7 \%$ (for the $5 \mathrm{mg}$ dose) and $8.33 \%$ (for the $25 \mathrm{mg}$ dose) of the initial dose, but this metabolite remained the most abundant one we recovered.

\section{Discussion}

One important - yet often overlooked issue - in the nutraceutical field is that of absorption and/or bioavailability of the active principle(s). This applies to omega 3 fatty acids, vitamins, and (poly)phenols. We here report that HT (one of the most popular and biologically active phenol) is absorbed and excreted when given as an olive mill waste water extract preparation. In particular, we recovered 8 to 10\% (as mole\%) of the administered HT in the urine and confirmed that most of it undergoes sulphation at the 3 ' position. To date, only one study has been published with pure HT (Gonzalez-Santiago et al., 2010), whereas many other ones report excretion of this phenol when given as component of extra virgin olive oil to rats or humans. Indeed, there is ample evidence of the $a b$ sorption and excretion of HT via extra virgin olive oil use, even though a comprehensive profile of its metabolites is being slowly developed. In the first report, Visioli et al. (2000) described how $30-60 \%$ of the administered HT was recovered in the urine, mostly as glucuronide conjugate. These data were subsequently confirmed by Vissers, Zock, Roodenburg, Leenen, and Katan (2002). Afterwards, more complete investigations (Miro-Casas et al., 2003) contributed to the near-complete elucidation of HT's metabolism in humans. More recently, HT sulphate has been proposed as a suitable biomarker for monitoring compliance with olive oil intake as its values in plasma or/and 24-h urine were significantly higher after extra virgin olive oil administration compared to baseline pre-intervention concentrations (Rubió et al., 2014). The data we present here reinforce this notion: HT-S-3' should be quantified in studies of HT as nutraceutical, to monitor compliance.

One unresolved issue is whether the extensive first-pass metabolism affects the manifold in vitro activities reported for HT and (poly)phenols in general. Indeed, this is an often overlooked aspect of (poly)phenol research and calls for more metabolite-based biochemical and molecular studies (Giordano et al., 2015), even though organ-specific deconjugation might, theoretically, yield pure HT and contribute to its biological activities (Giordano et al., 2015).

In conclusion, we prove that HT given as the foremost component of a nutraceutical preparation is bioavailable and is recovered in the urine chiefly as sulphate-3', which can be adopted as biomarker of extra virgin olive oil consumption. This is important in light of future HT-based nutraceutical formulations and epidemiological studies. 


\section{Acknowledgements}

This study was supported by a grant from the Ministerio de Ciencia e Innovación (AGL2011-28995) and co-funded by the "Marie Curie Amarout European Programme", European FEDER Funds, Programa de actividades en tecnologías ALIBIRD-CM S2013/ABU-2728 de la Comunidad de Madrid. The postdoctoral contract fellowship from the Spanish government awarded by the Ministry of Innovation and Science ("Juan de la Cierva" program) to Olha Khymenets is acknowledged. The authors wish to thank ACADELION Scientific and Medical Communications for critically reading and carefully editing this manuscript.

\section{Appendix: Supplementary material}

Supplementary data to this article can be found online at doi:10.1016/j.jff.2016.02.046.

R E F E R E N C E S

Caruso, D., Visioli, F., Patelli, R., Galli, C., \& Galli, G. (2001). Urinary excretion of olive oil phenols and their metabolites in humans. Metabolism: Clinical and Experimental, 50(12), 14261428. doi:10.1053/meta.2001.28073.

Crespo, M. C., Tome-Carneiro, J., Burgos-Ramos, E., Loria Kohen, V., Espinosa, M. I., Herranz, J., \& Visioli, F. (2015). One-week administration of hydroxytyrosol to humans does not activate Phase II enzymes. Pharmacological Research, 95-96, 132-137. doi:10.1016/j.phrs.2015.03.018.

EFSA Panel on Dietetic Products (2011). Scientific Opinion on the substantiation of health claims related to polyphenols in olive and protection of LDL particles from oxidative damage (ID 1333, 1638, 1639, 1696, 2865), maintenance of normal blood HDL cholesterol concentrations (ID 1639), maintenance of normal blood pressure (ID 3781), "anti-inflammatory properties" (ID 1882), "contributes to the upper respiratory tract health" (ID 3468), "can help to maintain a normal function of gastrointestinal tract" (3779), and "contributes to body defences against external agents" (ID 3467) pursuant to Article 13 (1) of Regulation (EC) No 1924/2006. EFSA Journal, 9 , 2033-2058.

Giordano, E., Dangles, O., Rakotomanomana, N., Baracchini, S., \& Visioli, F. (2015). 3-O-hydroxytyrosol glucuronide and 4-Ohydroxytyrosol glucuronide reduce endoplasmic reticulum stress in vitro. Food \& Function, 6, 3275-3281.

Gonzalez-Santiago, M., Fonolla, J., \& Lopez-Huertas, E. (2010). Human absorption of a supplement containing purified hydroxytyrosol, a natural antioxidant from olive oil, and evidence for its transient association with low-density lipoproteins. Pharmacological Research, 61(4), 364-370. doi:10.1016/j.phrs.2009.12.016.

Khymenets, O., Farré, M., Pujadas, M., Ortiz, E., Joglar, J., Covas, M. I., Solà, R., Farré, M., Saez, G., \& de la Torre, R. (2011). Direct analysis of glucoronidated metabolites of main olive phenols in human urine after dietary consumption of virgin olive oil. Food Chemistry, 126, 306-314.

Kotronoulas, A., Pizarro, N., Serra, A., Robledo, P., Joglar, J., Rubio, L., \& de la Torre, R. (2013). Dose-dependent metabolic disposition of hydroxytyrosol and formation of mercapturates in rats. Pharmacological Research, 77, 47-56. doi:10.1016/ j.phrs.2013.09.001.

Mahabir, S. (2014). Methodological challenges conducting epidemiological research on nutraceuticals in health and disease. PharmaNutrition, 2, 120-125.

Miro-Casas, E., Covas, M. I., Farre, M., Fito, M., Ortuño, J., Weinbrenner, T., Roset, P., \& de la Torre, R. (2003). Hydroxytyrosol disposition in humans. Clinical Chemistry, 49(6), 945-952.

Perez-Mana, C., Farre, M., Pujadas, M., Mustata, C., Menoyo, E., Pastor, A., Langohr, K., \& de la Torre, R. (2015a). Ethanol induces hydroxytyrosol formation in humans. Pharmacological Research, 95-96, 27-33. doi:10.1016/j.phrs.2015.02.008.

Perez-Mana, C., Farre, M., Rodriguez-Morato, J., Papaseit, E., Pujadas, M., Fito, M., \& de la Torre, R. (2015b). Moderate consumption of wine, through both its phenolic compounds and alcohol content, promotes hydroxytyrosol endogenous generation in humans. A randomized controlled trial. Molecular Nutrition \& Food Research, 59(6), 1213-1216. doi:10.1002/mnfr.201400842.

Rubió, L., Farras, M., de la Torre, R., Macià, A., Romero, M. P., Valls, R. M., Sola, R., Farre, M., Fito, M., \& Motilva, M. J. (2014). Metabolite profiling of olive oil and thyme phenols after a sustained intake of two phenol-enriched olive oils by humans: Identification of compliance markers. Food Research International, 65, 59-68.

Tome-Carneiro, J., \& Visioli, F. (2015). Polyphenol-based nutraceuticals for the prevention and treatment of cardiovascular disease: Review of human evidence. Phytomedicine: International Journal of Phytotherapy and Phytopharmacology, doi:10.1016/j.phymed.2015.10.018.

U.S. Department of Health and Human Services. Guidance for Industry. Bioanalytical Method Validation. (2001).

Visioli, F., \& Bernardini, E. (2011). Extra virgin olive oil's polyphenols: Biological activities. Current Pharmaceutical Design, 17(8), 786-804.

Visioli, F., Galli, C., Bornet, F., Mattei, A., Patelli, R., Galli, G., \& Caruso, D. (2000). Olive oil phenolics are dose-dependently absorbed in humans. FEBS Letters, 468(2-3), 159-160.

Vissers, M. N., Zock, P. L., Roodenburg, A. J., Leenen, R., \& Katan, M. B. (2002). Olive oil phenols are absorbed in humans. The Journal of Nutrition, 132(3), 409-417. 